\title{
Chemorefractory extranodal nasal-type natural-killer/T-cell lymphoma with great response to pembrolizumab in a young patient: a case report
}

Fatemeh Adabifirouzjaei ${ }^{1}$, Bharam Khazai ${ }^{2}$, Ghazaleh Azami ${ }^{3}$ and Ghazaleh Shoja-e-Razavi ${ }^{4^{*}}$

\begin{abstract}
Introduction: Extranodal, natural-killer/T-cell lymphoma of nasal type is a rare but aggressive disease usually presenting as progressive necrotic lesions in the nasal cavity that responds poorly to chemotherapy. In this paper, we report a relapsing, chemorefractory case of extranodal natural-killer/T-cell lymphoma responding to checkpoint inhibitor immunotherapy with pembrolizumab.
\end{abstract}

Case presentation: A 32-year-old Hispanic woman with a history of recurrent sinusitis and preseptal abscess presented with a hoarse voice, swelling around the right eye, and diplopia. Laryngoscopy showed infiltrating tissue extending to bilateral laryngeal ventricles and false vocal cords. On immunohistochemical examination of laryngeal biopsy, the neoplastic cells showed positivity for CD3 (cytoplasmic), CD7, CD56, granzyme B, CD30, and Epstein-Barr virus-encoded ribonucleic acid (RNA). Extranodal natural-killer/T-cell lymphoma, nasal type, was confirmed. In the absence of distant organ involvement, the decision was to perform chemotherapy with etoposide, ifosfamide, mesna, cisplatin, and dexamethasone (VIPD protocol) followed by concurrent chemoradiation with weekly doses of cisplatin and two cycles of VIPD as adjuvant treatment. However, 1 month after completion of the treatment; disease recurrence was demonstrated. The patient was scheduled to receive salvage chemotherapy with steroid, methotrexate, ifosfamide, L- asparaginase, and etoposide (SMILE) protocol and CD30-targeting monoclonal antibodies. However, the mass was chemorefractory without response to either L-asparaginase-based salvage chemotherapy in combination with high-dose methotrexate or brentuximab vedotin. However, this case of chemorefractory extranodal naturalkiller/T-cell lymphoma, nasal type, responded well to the novel drug pembrolizumab, which was able to control the disease.

Conclusion: Checkpoint inhibitors are potential treatment option in selected chemorefractory extranodal naturalkiller/T-cell lymphoma, nasal type, cases.

Keywords: Extranodal NK/T-cell lymphoma, Epstein-Barr virus, L-Asparaginase, High-dose methotrexate, Brentuximab vedotin, Pembrolizumab, Case report

\footnotetext{
*Correspondence: ghazaleh.shojaerazavi@ucalgary.ca

${ }^{4}$ Hematology and oncology Section, Division of Hematology

and Oncology, Internal Medicine Department, School of Medicine, The University of Calgary, Alberta, Canada

Full list of author information is available at the end of the article
}

\section{Introduction}

Extranodal, nasal-type natural-killer (NK)/T-cell lymphoma is a rare and aggressive type of lymphoma. Although there is no standard treatment approach for the disease, the preferred approach in the localized disease original author(s) and the source, provide a link to the Creative Commons licence, and indicate if changes were made. The images or other third party material in this article are included in the article's Creative Commons licence, unless indicated otherwise in a credit line to the material. If material is not included in the article's Creative Commons licence and your intended use is not permitted by statutory regulation or exceeds the permitted use, you will need to obtain permission directly from the copyright holder. To view a copy of this licence, visit http://creativecommons.org/licenses/by/4.0/. The Creative Commons Public Domain Dedication waiver (http://creativeco mmons.org/publicdomain/zero/1.0/) applies to the data made available in this article, unless otherwise stated in a credit line to the data. 
is chemoradiation and, in advanced cases, combination chemotherapy [1].

\section{Case presentation}

A 32-year-old Hispanic woman, G1P1L1, stay-at-home mom, with a history of recurrent sinusitis and preseptal abscess for 2 years presented with a hoarse voice, swelling around the right eye, and diplopia in July 2018. She was previous a cocaine (occasionally since 2015) user for 2 years, who had quit it 2 years before presenting to the hospital. She had no family history of cancer or hematological diseases. She had a blood pressure of $124 / 81 \mathrm{mmHg}$, heart rate of 113 beats per minute, and temperature of $37.1^{\circ} \mathrm{C}$ on first admission. On physical examination, swelling of the right orbit, including the eyelid, was noted. Nasal examination showed some erythema to the nasal mucosa but no perforated septum and no saddle nose deformity. There was no inflammation in the ears, and the inner ears looked normal with normal tympanic membranes. On neurological examination, limited eye movements on the right side with no ability for abduction or adduction indicating extraocular muscle involvement were detected. Sinus mucosa biopsy showed chronic inflammation featuring heavy perivascular infiltration of mixed lymphoplasmacytic cells and histiocytes. Despite being on prednisone owing to the primary impression of autoimmune nature of the disease, over a period of 3-4 months, there was progression of symptoms causing hoarse voice and further swelling around the right eye, diplopia, and limitation of right eye movement. Complete blood count results revealed $9 \times 10^{3}$ white blood cells with $6 \times 10^{3}$ neutrophils, $2 \times 10^{3}$ lymphocytes, and $1 \times 10^{3}$ monocytes, with no eosinophils and basophils. Hemoglobin level was $14.4 \mathrm{~g} / \mathrm{L}$, and platelet count was $328 \times 10^{3} / \mu \mathrm{L}$. The other blood test results were as follows: creatinine $0.75 \mu \mathrm{mol} / \mathrm{L}$, urea $1.9 \mathrm{mg} / \mathrm{dL}$, aspartate aminotransferase 15 units/L, alanine aminotransferase 26 units/L, alkaline phosphatase 89 units/L, and gamma glutamyl transferase 42 units/L.

Direct laryngoscopy in December 2018 showed infiltrating tissue involving laryngeal ventricles bilaterally extending towards the anterior aspect of false vocal cords. Magnetic resonance imaging (MRI) of the orbit also showed infiltration and enlargement of the right medial rectus muscle.

Both laryngeal infiltrating lesions and medial rectus muscle of the right eye were biopsied. On immunohistochemical examination of laryngeal infiltration biopsy, the neoplastic cells showed diffuse positivity for cluster of differentiation (CD)3 (cytoplasmic), CD7, CD56, granzyme B, CD30, and multiple myeloma oncogene-1 (MUM1). Results were negative for CD5, CD4,
CD8, CD10, CD20, and PAX5. In situ hybridization study was positive for Epstein-Barr virus (EBV)-encoded ribonucleic acid (EBER). Monoclonal T-cell receptor (TCR) gene arrangement was detected by polymerase chain reaction (PCR) (Fig. 1).

Nasal-type extranodal NK/T-cell lymphoma was confirmed. Right medial rectus muscle biopsies, however, were negative for lymphoma with a confirmed negative TCR by PCR. Investigation for human immunodeficiency virus (HIV) and human T-cell leukemia/lymphoma virus (HTLV1) was negative. Bone marrow aspiration and biopsy were also negative. Fluorodeoxyglucose (FDG)positron emission tomography (PET) computed tomography $(\mathrm{CT})$ scan at the time of diagnosis (Fig. 2) showed a discrete hypermetabolic focus in the right medial rectus muscle corresponding to the area of greatest thickening. Mild residual mucosal thickening was seen in the maxillary antra and nasal mucosa. A focal hypermetabolic area was noted in the anterior laryngeal soft tissues adjacent to the intrinsic laryngeal muscles indicating viable lymphoma. There was no metabolic activity in the rest of body based on the PET CT results.

Since the lymphoma was localized to the laryngeal area with no systemic involvement, the patient received one cycle of chemotherapy in February 2019 with VIPD protocol containing etoposide $\left(100 \mathrm{mg} / \mathrm{m}^{2}\right.$, intravenous infusion, days $1-3)$, ifosfamide $\left(1200 \mathrm{mg} / \mathrm{m}^{2}\right.$, intravenous infusion, once a day, days $2-4)$, mesna $\left(330 \mathrm{mg} / \mathrm{m}^{2}\right.$ of mesna was given before ifosfamide, and $480 \mathrm{mg} / \mathrm{m}^{2}$ was given 4 and 8 hours after infusion for 3 subsequent days , intravenous infusion, three times a day), cisplatin (33 $\mathrm{mg} / \mathrm{m}^{2}$, intravenous infusion, weekly), and dexamethasone (40 mg, once daily, days $1-4$, with G-CSF support). Two more cycles of VIPD were also scheduled in April and May of 2019, after the completion of chemoradiation. FDG-PET CT scan after completion of treatment was done in June 2019 and did not show convincing metabolic activities to suggest residual viable lymphoma. The previously noted hypermetabolic soft-tissue nodule at the anterior aspect of the larynx was resolved.

However, within a month after the PET-CT scan featuring complete metabolic response, the patient presented with an enlarged right-sided submandibular infiltrative mass. CT scan showed asymmetric mass in submandibular glands area that was bulkier in the right and demonstrated heterogeneous enhancement in favor of recurrent disease. Orbital CT scan also reported an asymmetric soft-tissue mass and stranding involving the right preseptal and periorbital fat predominantly at the inferior aspect of the periorbital tissue.

A repeat biopsy from the right lower eyelid confirmed involvement by the previously diagnosed nasal-type EBER-positive extranodal NK/T-cell lymphoma. 

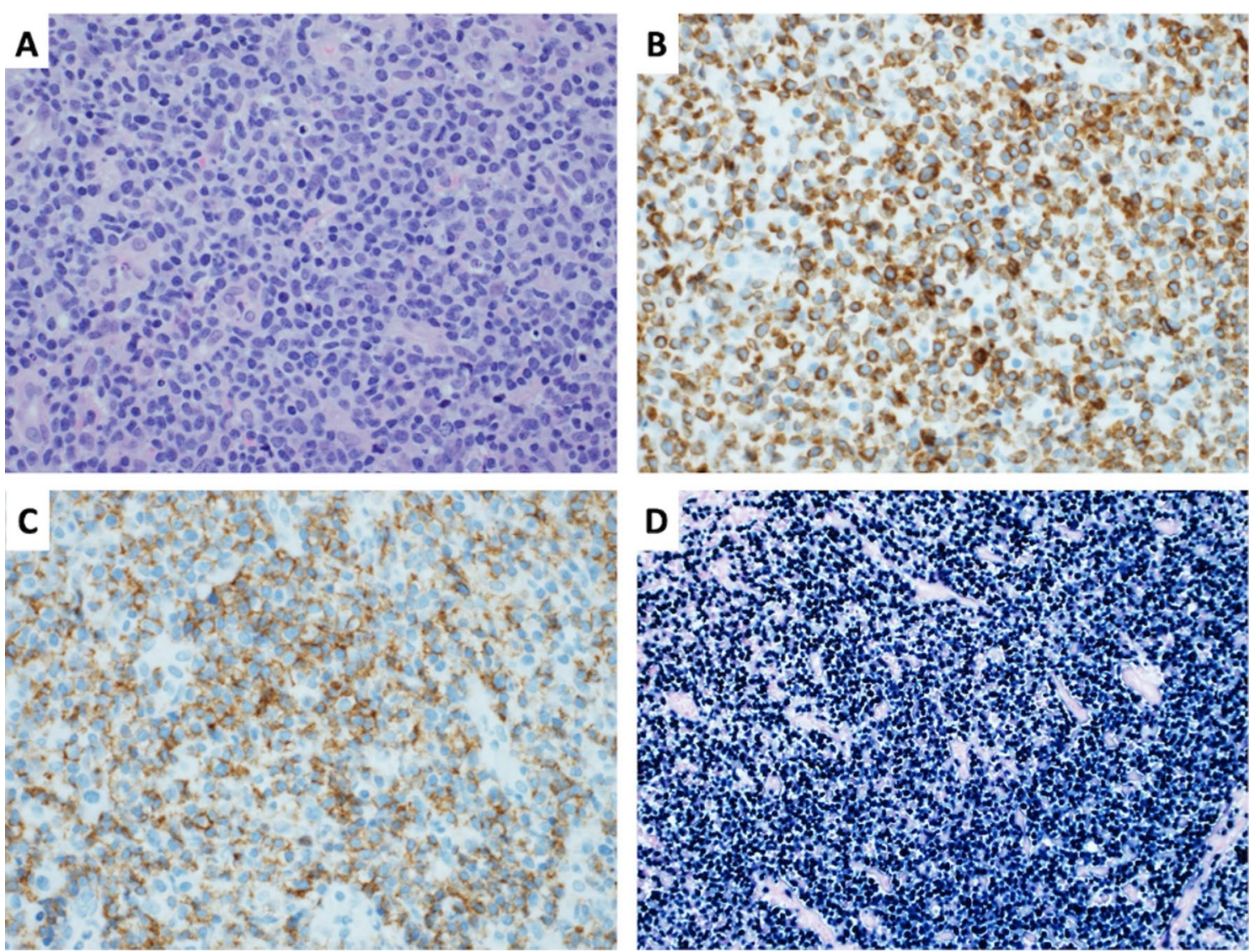

Fig. 1. Photomicrographs illustrating the salient features on histomorphology. This figure shows the salient features on histomorphology of the patient's laryngeal biopsy with $\mathbf{A}$ hematoxylin and eosin, 40x; B CD3 antibody stain demonstrating cytoplasmic (cCD3-epsilon) staining pattern; C CD56 antibody stain $>75 \%$ of the tumor cells; $\mathbf{D}$ EBV-encoded small RNA (EBER) by in situ hybridization technique
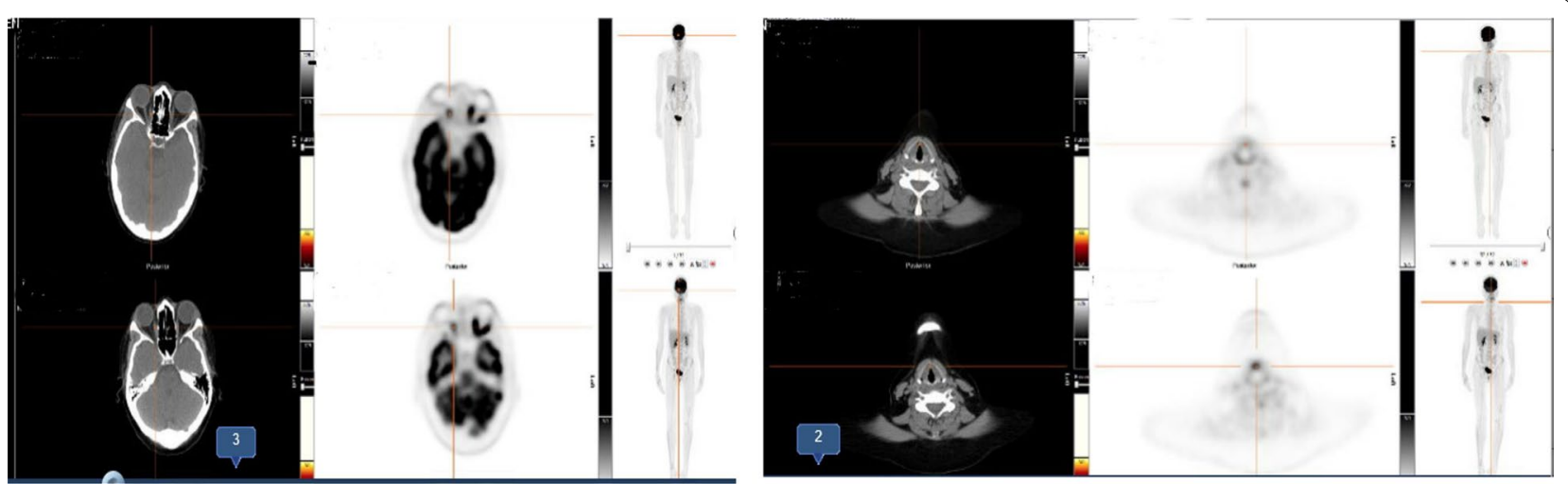

Fig. 2. Fluorodeoxyglucose- positron emission tomography (FDG-PET) images of patient, before starting pembrolizumab. FDG PET shows a discrete focus of hypermetabolism in the medial rectus muscle on the right corresponding to the area of greatest thickening, suggestive of residual lymphoma as physiologic activity in the other extraocular muscles on the right is absent. There is a focal area of hypermetabolism within the anterior soft tissues adjacent to the intrinsic laryngeal musculature in keeping with viable lymphoma in laryngeal area 
Systemic investigation did not show any distant involvement. The patient was scheduled to receive salvage chemotherapy with SMILE protocol in August and September 2019 [oral methotrexate $2 \mathrm{~g} / \mathrm{mg}$, orally, on day 1 , leucovorin $15 \mathrm{mg}$, intravenous infusion, four times a day, on days $2-4$, ifosfamide $1500 \mathrm{mg} / \mathrm{m}^{2}$, intravenous infusion, on days $2-4$, mesna $300 \mathrm{mg} / \mathrm{m}^{2}$, intravenous infusion, once daily, on days $2-4$, dexamethasone $40 \mathrm{mg}$, daily, on days $2-4$, etoposide $100 \mathrm{mg} / \mathrm{m}^{2}$, intravenous infusion, on days $2-4$, L-asparaginase $6000 \mathrm{U} / \mathrm{m}^{2}$, intramuscular, on days $8,10,12,14,16,18$, and 20 , granulocyte colony-stimulating factor (GCSF) support from day 6 and discontinued if the leukocyte count exceeded $5000 / \mu \mathrm{L}]$. Tumor cells also showed CD30 expression; thus, CD30-targeting monoclonal antibody, brentuximab vedotin $(1.8 \mathrm{mg} / \mathrm{kg}$ every 3 weeks $)$ was added to the treatment in October 2019. Salvage chemotherapy with SMILE protocol was complicated with neutropenia and thrombocytopenia. In addition, brentuximab vedotin induced grade 3 sensory and motor neuropathies in both lower extremities while the disease did not respond to the treatment.

Subsequently, pembrolizumab was given at the dose of $100 \mathrm{mg}$ every 3 weeks starting December 2019 with a clinical response after the third cycle of treatment, and the patient remained disease-free on this treatment. Orbital and cervical MRI figures during this therapy are shown in Fig. 3. The patient is currently alive and disease-free with grade 2 motor neuron toxicity on the left ankle that has remained unchanged since chemotherapy with brentuximab vedotin. The swelling of the eye and voice changes are completely back to normal. The patient's Eastern Cooperative Oncology Group (ECOG) performance status is 1 . Fatigue and mild nausea are ongoing adverse events that she has been experiencing. Both symptoms are considered to be grade 2 and are not impairing the patient's quality of life. Her last follow-up in the cancer center was on 10 June 2021.

\section{Discussion}

NK/T-cell lymphomas almost exclusively involve nonnodal sites and are, hence, called extranodal NK/T-cell lymphoma (ENKTL). In nearly $80 \%$ of patients, the initial presentation sites include the oropharynx, the Waldeyer's ring, and the upper aerodigestive tract [1]. The pathogenesis of ENKTL remains unknown; however, recent genomic data have revealed a complex interaction between the Janus kinase (JAK)/signal transducer and activator of transcription (STAT) pathways, epigenetic dysregulation, disrupted nuclear factor kappalight-chain-enhancer of activated B cells (NFkB), and mitogen-activated protein kinase (MAPK) pathways as a possible pathophysiology behind this lymphoma [2].

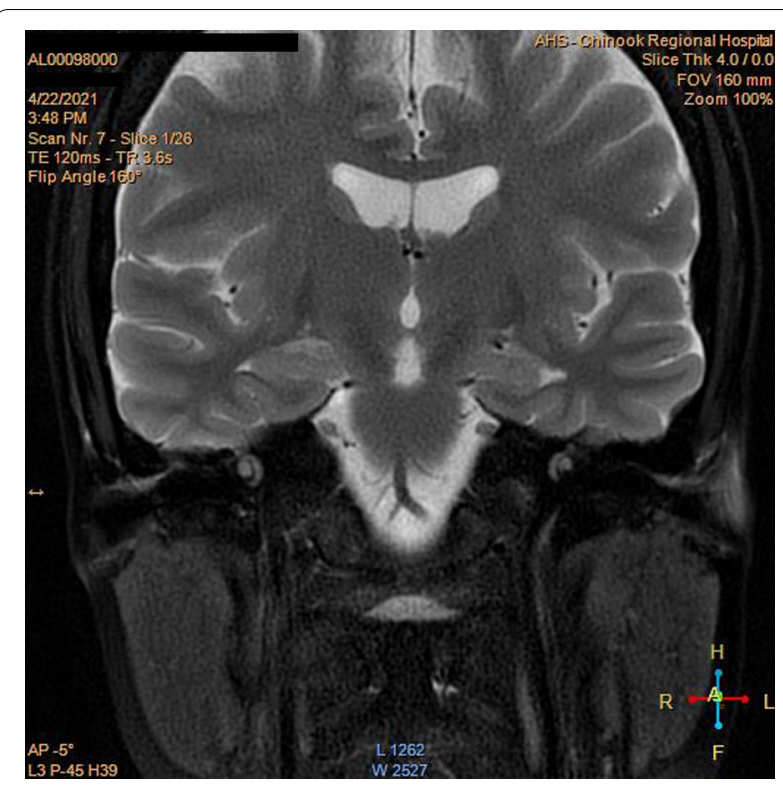

Fig. 3. Orbit and cervical MRI of patient during pembrolizumab therapy. Magnetic resonance imaging (MRI) show symmetric appearance of the larynx, vocal cords, and hypopharynx soft tissues. Submandibular glands have a fairly symmetric appearance. Previously seen abnormality on the right is not present today. There is no evidence of identified adenopathy or abnormal soft-tissue enhancement

Histological confirmation of the disease is essential and should reveal neoplastic lymphoid cells associated with plasma cells, polymorphonuclear neutrophils, and histiocytes presenting in an angiocentric pattern [3]. Due to expression of cytokines and cytotoxic molecules by the tumor cells, fibrinoid or coagulative necrosis may be seen in these patients. CD56 or EBER staining is helpful in this setting. The lymphoma cells express CD2 and CD3e, but usually not CD3s or other T-cell markers (CD4, CD5, and CD8) [4].

EBV+ T- and NK-cell lymphoma frequently expresses CD30.These cells always express EBER and cytotoxic molecules (TIA-1, perforin, or granzyme B) [5].

Plasma EBV DNA concentration is proportional to the tumor bulk; therefore, quantification of EBV DNA can be useful for both baseline prognostication and future monitoring [6]. ENKTL is F18-FDG avid, and PET-CT is now considered a standard imaging modality for this type of lymphoma. Conventional lymphoma treatments such as CHOP are ineffective in ENKTL [7]. Either chemotherapy followed by radiotherapy or concurrent chemoradiotherapy can be considered as the first-line treatment for stage I/II ENKTL patients. L-asparaginase-containing regimens are efficacious for the treatment of stage III/IV ENKTL, and the SMILE regimen is the standard therapy [8]. 


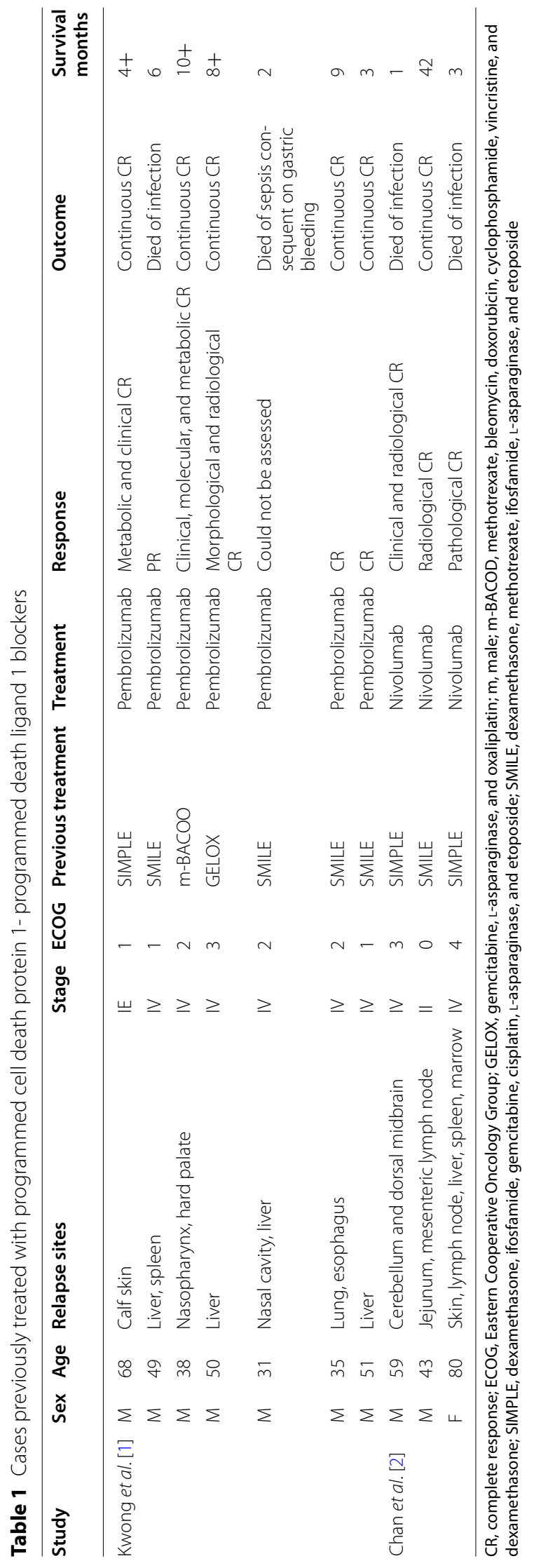


Novel immunotherapies are considered for advancedstage or relapsed/refractory ENKTCL (Table 1) [9-11]. Given that programmed death ligand 1 (PD-L1) is expressed in a substantial portion of ENKTL, it is an important biomarker that is widely used for patient selection for immunotherapy [12]. Pembrolizumab blocks PD-L1 owing to EBV-driven overexpression of the latent membrane proteins [latent membrane protein 1 (LMP1) and LMP2] with activation of the NF- $\mathrm{KB} / \mathrm{MAPK}$ pathways [13]. Patients failing L-asparaginase regimens and allogeneic hematopoietic stem cell transplantation (HSCT) have been successfully treated with pembrolizumab [14]

\section{Conclusion}

We presented a case of a 32-year-old woman with a history of recurrent sinusitis and preseptal abscess who presented with pansinusitis. Laryngoscopy showed infiltrating tissue extending to bilateral laryngeal ventricles and false vocal cords. On immunohistochemical examination of laryngeal biopsy, ENKTCL-NT was confirmed. The patient was refractory to both VIPD and SMILE protocols, and CD30-targeting monoclonal antibodies. The patient responded well to pembrolizumab despite rapid progression after chemoradiotherapy. Unlike salvage chemotherapy and CD30-targeted immunotherapy with grade 3 toxicities, immunotherapy with pembrolizumab was tolerated well with minimal grade $1-2$ toxicity. This case suggests checkpoint inhibitors as a potential treatment option in selected chemorefractory ENKTCL-NT cases.

\section{Patient perspective}

The patient was very happy with being switched from high-dose chemotherapy that needed hospitalization to outpatient immunotherapy. In fact, she has tolerated immunotherapy with minimal side effects, mostly mild fatigue. She has been very happy with the results, including the overall disease control as well as resolution of the eye swelling and the change of voice back to normal.

\section{Abbreviations \\ EBER: Epstein-Barr virus-encoded RNA; EBV: Epstein-Barr virus; ENKTCL: Extranodal natural-killer/T-cell lymphoma; ENKTCL-NT: Extranodal natural- killer/T-cell lymphoma, nasal type; NHL: Non-Hodgkin lymphoma.}

\section{Acknowledgements}

The authors thank Dr. Carolyn Owen MD, FRCP(C), associate professor in the Division of Hematology \& Hematological Malignancies at the University of Calgary, and Adnan Mansoor, MD, FCPS, FRCP(C), FCAP, professor in the Division of Hematopathology, Department of Pathology and Laboratory Medicine at the University of Calgary, for their support and comments on the manuscript.

\section{Authors' contributions}

FA: acquisition of data, drafting the manuscript. BK: reviewing the manuscript, GA: drafting the manuscript. GS: visiting and treating the patient, critical revision of the manuscript. All authors read and approved the final manuscript.

\section{Funding}

The authors received no financial support for this publication.

\section{Availability of data and materials \\ Not applicable.}

\section{Declarations}

Ethics approval and consent to participate

No ethical approval is needed for the study.

\section{Consent for publication}

Written informed consent was obtained from the patient for publication of this case report and any accompanying images. A copy of the written consent is available for review by the Editor-in-Chief of this journal.

\section{Competing interests}

The authors declare that they have no competing interests.

\section{Author details}

${ }^{1}$ Sulpizio Cardiovascular Center, University of California San Diego, San Diego, California, USA. ${ }^{2}$ Harbor-UCLA Medical Center, University of California Los Angeles, Torrance, CA, USA. ${ }^{3}$ Internal Medicine Department, School of Medicine, Mashhad University of Medical Sciences, Mashhad, Iran. ${ }^{4}$ Hematology and oncology Section, Division of Hematology and Oncology, Internal Medicine Department, School of Medicine, The University of Calgary, Alberta, Canada.

Received: 19 May 2021 Accepted: 25 August 2021

Published online: 26 October 2021

\section{References}

1. Tse E, Kwong YL. The diagnosis and management of NK/T-cell lymphomas. J Hematol Oncol. 2017;10(1):85. https://doi.org/10.1186/ s13045-017-0452-9.

2. Somasundaram N, Lim JQ, Ong CK, Lim ST. Pathogenesis and biomarkers of natural killer T cell lymphoma (NKTL). J Hematol Oncol. 2019;12(1):105. https://doi.org/10.1186/s13045-019-0717-6.

3. Taali L, Abou-Elfadl M, Fassih M, Mahtar M. Nasal NK/T-cell lymphoma: a tragic case. Eur Ann Otorhinolaryngol Head Neck Dis. 2017;134(2):121-2. https://doi.org/10.1016/j.anorl.2016.08.006.

4. de Mel S, Li JB, Abid MB, Tnag T, Tay HM, Ting WC, et al. The utility of flow cytometry in differentiating NK/T cell lymphoma from indolent and reactive NK cell proliferations. Cytom B Clin Cytom. 2018;94(1):159-68. https:// doi.org/10.1002/cyto.b.21529.

5. Kim WY, Montes-Mojarro IA, Fend F, Quintanilla-Martinez L. Epstein-Barr virus-associated T and NK-cell lymphoproliferative diseases. Front Pediatr. 2019;7:1-18. https://doi.org/10.3389/fped.2019.00071.

6. Kanakry JA, Hegde AM, Durand CM, Massie AB, Greer AE, Ambinder $R F$, Valsamakis A. The clinical significance of ebv DNA in the plasma and peripheral blood mononuclear cells of patients with or without ebv diseases. Blood. 2016;127(16):2007-17. https://doi.org/10.1182/ blood-2015-09-672030.

7. Suzuki R. NK/T cell lymphoma: updates in therapy. Curr Hematol Malig Rep. 2018;13(1):7-12. https://doi.org/10.1007/s11899-018-0430-5.

8. Ando M, Sugimoto K, Kitoh T, Sasaki M, Mukai K, Ando J, et al. Selective apoptosis of natural killer-cell tumours by L-asparaginase. Br J Haematol. 2005. https://doi.org/10.1111/j.1365-2141.2005.05694.x.

9. Hu B, Oki Y. Novel immunotherapy options for extranodal NK/T-cell lymphoma. Front Oncol. 2018;8:139. https://doi.org/10.3389/fonc.2018. 00139.

10. Kwong YL, Chan TSY, Tan D, et al. PD1 blockade with pembrolizumab is highly effective in relapsed or refractory NK/T-cell lymphoma failing 
L-asparaginase. Blood. 2017;129(17):2437-42. https://doi.org/10.1182/ blood-2016-12-756841.

11. Chan TSY, Li J, Loong F, Khong PL, Tse E, Kwong YL. PD1 blockade with low-dose nivolumab in NK/T cell lymphoma failing L-asparaginase: efficacy and safety. Ann Hematol. 2018;97(1):193-6. https://doi.org/10.1007/ s00277-017-3127-2.

12. Du L, Zhang $L$, Li L, Xin L, Jiagin $Y$, Wang $X$, et al. Effective treatment with PD-1 antibody, chidamide, etoposide, and thalidomide (PCET) for relapsed/refractory natural killer/T-cell lymphoma: a report of three cases. Onco Targets Ther. 2020. https://doi.org/10.2147/OTT.S262039.

13. Cho J, Kim SJ, Park WY, Kim J, Woo J, Kim G, et al. Immune subtyping of extranodal NK/T-cell lymphoma: a new biomarker and an immune shift during disease progression. Mod Pathol. 2020;33(4):603-15. https://doi. org/10.1038/s41379-019-0392-8.

14. Kim SJ, Hyeon J, Cho I, Ko YH, Kim WS. Comparison of efficacy of pembrolizumab between Epstein-Barr virus-positive and -negative relapsed or refractory non-Hodgkin lymphomas. Cancer Res Treat. 2019:51(2):611 22. https://doi.org/10.4143/crt.2018.191.

\section{Publisher's Note}

Springer Nature remains neutral with regard to jurisdictional claims in published maps and institutional affiliations.
Ready to submit your research? Choose BMC and benefit from:

- fast, convenient online submission

- thorough peer review by experienced researchers in your field

- rapid publication on acceptance

- support for research data, including large and complex data types

- gold Open Access which fosters wider collaboration and increased citations

- maximum visibility for your research: over 100M website views per year

At BMC, research is always in progress.

Learn more biomedcentral.com/submissions 